\title{
A feasibility report of a novel and unpublished surgical approach for Spiegel's hernia: reconstruction using robotics-assisted surgery
}

This article was published in the following Dove Press journal:

Advanced Health Care Technologies

17 April 2015

Number of times this article has been viewed

\author{
Eduardo H Pirolla ${ }^{1,2}$ \\ Felipe Fregni ${ }^{3}$ \\ Alexandre L Godoy-Santos ${ }^{1,4}$ \\ Vladimir Schraibman ${ }^{5}$ \\ 'Sírio-Libanês Hospital, São Paulo, \\ Brazil; ${ }^{2}$ Spaulding Rehabilitation \\ Network Research Laboratory, \\ Harvard Medical School, \\ ${ }^{3}$ Spaulding Rehabilitation Network, \\ Massachusetts General Hospital- \\ Harvard Medical School, Boston, MA, \\ USA; ${ }^{4}$ Department of Orthopedics \\ and Traumatology, Federal University \\ of São Paulo, São Paulo, Brazil; \\ ${ }^{5}$ Department of Gastrointestinal \\ Surgery, Federal University of São \\ Paulo, São Paulo, Brazil
}

\begin{abstract}
The Spigelian hernia or Spiegel's hernia is rarely found, with less than 900 cases reported in medical literature. It was first described by J T Klinkosch in 1764 and was named by Adriaan van den Spieghel. The etiology of the hernia may be related to predisposing factors such as weakness of the abdominal wall by the insertion of vascular structures next to the semilunar or arcuate line of Douglas. However, some factors such as obesity, chronic bronchopneumopathies, and pregnancy may be associated with the etiology. Anatomically, most of these hernias occur between the lateral border of the rectus abdominis muscle and the lateral semilunar or Spigelian line that marks the transition of the transversus abdominis muscle to the aponeurosis. Spiegel's hernia can cause serious cases of organ incarceration because its diagnosis is often made at a late stage. Laparoscopic surgery is now an established method for itstreatment. We describe a surgical treatment unprecedented in the literature of Spiegel's hernia with a new procedure: the da Vinci Robotic System. This article also provides in detail the technical advantages and reliability of the robotics-assisted surgical approach on the patient. Robotics-assisted surgical repair for Spiegel's hernia has never been carried out or published previously. The authors show two cases of correction of Spiegel's hernia through surgical robotics, with the use of a mesh-type and double-sided peritoneum suture and the hernia ring suture. Advantages of the robotic approach in relation to laparoscopic technique are highlighted. A systematic review of relevant literature and the history of Spiegel's hernia are reported. The pain score was lower than that reported in pure laparoscopic surgery reports. This may be related to the increased stability of the trocar approach in robotics. It was technically easier to visualize the anterior wall and to suture this site through robotic surgery when compared to the laparoscopic approach. The robotic surgery has proven to be a procedure with significant advantages in terms of intraoperative techniques and postoperative clinical care. However, new cases should be evaluated with a larger follow-up for new conclusions.
\end{abstract}

Keywords: hernia, robotic, reliability, outcome

\section{Introduction}

Spiegel's hernia is defined as a hernia of the abdominal wall; it is hard to diagnose and when diagnosed, it is at a late stage. Since it is a very hard condition to diagnose, it requires a high level of attention and high index of suspicion, given the lack of patient symptoms and signs. ${ }^{1,2}$ With fewer than 900 cases reported in literature, corresponding to $1 \%-2 \%$ of all hernias, Spiegel's hernia should be considered when bulges are present in the lateral and lower abdominal walls. Its highest incidence is between 40-70 years of age in both sexes, often related to obesity. ${ }^{2-4}$

In general, it is a hernia ring developed in the vicinity of the semicircular or arcuate line of Douglas, with protrusion of preperitoneal fat, peritoneal pouch, and visceral
Correspondence: Eduardo H Pirolla Spaulding Rehabilitation Network, Harvard Medical School, 96 I3th Street, Charlestown, Boston, MA 02129, USA Tel +55 || 323| 3737/+| 8572347332 Email eduardopirolla@gmail.com 
organ, by means of a congenital defect or weakness in the Spigelian fascia. ${ }^{1,5}$ Anatomically, the integrity of the lateral wall of the abdomen is maintained by the intersection and overlapping of fibers of the transversus abdominis muscle with the external and internal oblique abdominis muscles, which support the underlying transversalis fascia. Adriaan van den Spiegel was the first to describe the semilunar line that merges the rectus muscle with the internal oblique aponeurosis. ${ }^{1,6,7}$ Often, the herniated sac in Spiegel's hernia (Figure 1) remains above the epigastric vessels and the Hesselbach ligament, projecting into the Hesselbach triangle, which can often be a cause of either delay in diagnosis or wrong diagnosis ${ }^{1,7,8}$.

Some cases of herniated Spiegel's line or Spigelian line are diagnosed as giant lipomas of the abdominal wall, or incision hernias, especially in women who have undergone cesarean procedure. Many of these patients end up in emergency rooms with symptoms and signs of acute abdominal obstruction or ischemia, and after inconclusive examinations, undergo exploratory laparotomy or laparoscopy in the best care centers. ${ }^{8}$ In two of our five cases of Spiegel's hernia treated by laparoscopic surgery, the emergency room of another hospital had diagnosed the hernias as giant lipomas. The patients complained of severe abdominal pain when in dorsal flexion of the abdomen or when required to pick something up from the ground. One of the most serious and severe complications of a Spiegel's hernia is bowel incarceration and subsequent necrosis. Because of possible diagnostic difficulties, laparoscopic exploratory surgery is indicated in these early cases due to the many intraoperative possibilities that can solve the case and avoid further surgery and/or serious complications. ${ }^{8-10}$

In the past, preoperative diagnosis of Spiegel's hernia was performed in only $50 \%$ of cases. ${ }^{11,12}$ The diagnoses began to be made earlier with the advent and use of ultrasonography ( $70 \%$ of the cases). With the advent of the computed tomography (CT) scan, especially the multislice model, diagnosis rates, when the examination is requested, can reach up to $100 \%$ of the cases. ${ }^{13} \mathrm{CT}$ is the gold standard for diagnosis of this type of hernia, especially in difficult cases, eg, situations in literature where, mistakenly, acute diverticulitis was diagnosed (Figure 2). ${ }^{13,14}$ Other differential diagnoses include appendicitis, abscesses of appendicitis, tumors of the abdominal wall (eg, desmoid tumors, myxoid tumors, and so on), spontaneous hematoma of the abdominal rectus muscle, and acute diverticulitis. Often, incisional hernias of the lower floor of the abdomen or inguinal canal can be taken into consideration. ${ }^{4,13,15}$

The Belgian anatomist Adriaan van den Spiegel (Adrianus Spigelius), and disciple of the Italian anatomist Girolamo Fabrici, in Padua, was the first to describe the semilunar line in 1645, now known as Spiegel's line ("Linea Spigeli”). Josef Thaddaei Klinkosch, a Flemish anatomist and lecturer at the University of Padua, made the first description of this type of hernia in 1764, in his text and program entitled "Divisionem Herniarum, Novam-Que Herniae Ventralis Speciem"; he was also the first to use the name Spigelian hernia. ${ }^{3,4,6,8,16,17}$ Henri François Le Dran gave the first description of a break along the semilunar line in $1742 .{ }^{18}$ In 1746 , Beatus Ignatius la Chausse described the first classification, with the division of ventral hernias in groups, publishing his paper in $1756 .{ }^{19}$ In 1935 , the Italian surgeon Scoppinaro reported the first case of Spiegel's hernia in a child..$^{20} \mathrm{Al}$-Salem, a pediatric surgeon, wrote that such hernias are very rare in children, with only 40 reported cases until the early 21 st century. ${ }^{21}$

In the first anatomical and congenital study by Sir Astley Cooper (1804), ${ }^{22}$ he described the etiology of Spiegel's hernia by the prolapse of the abdominal contents through the aponeurosis of the transversus muscle via the opening of perforated vessels and nerves of the abdominal wall. This was denominated the "vascular theory", and it has been the accepted surgical etiology for more than 150 years. ${ }^{22}$ Read,

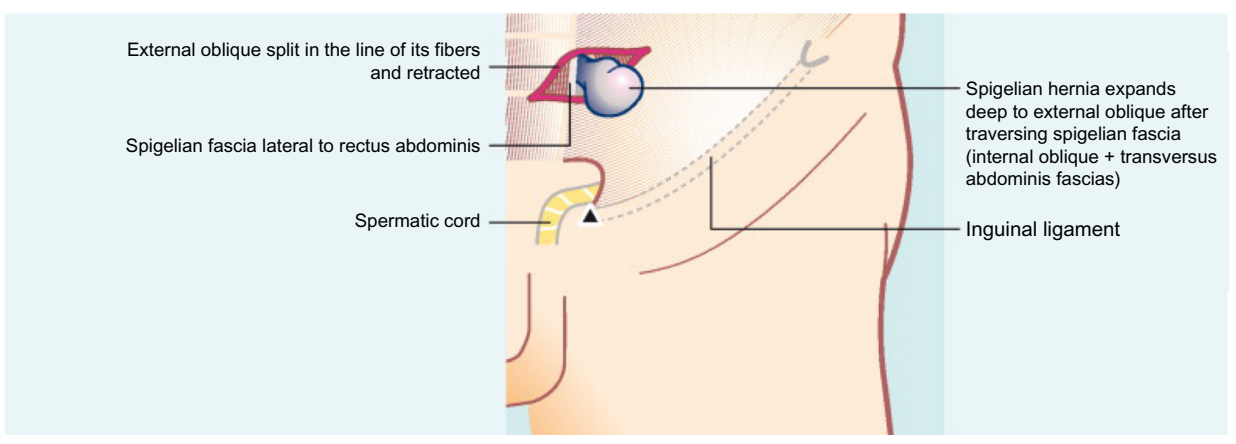

Figure I Spiegel's hernia: male anatomic view. 


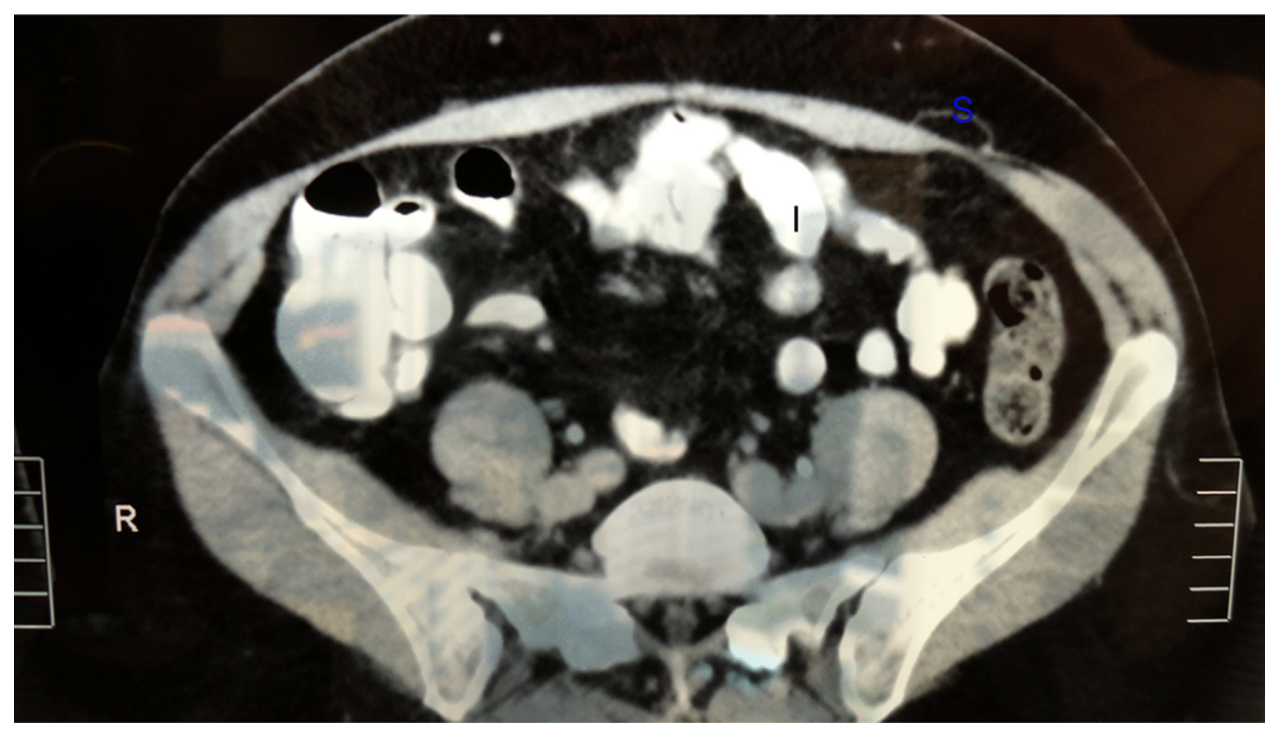

Figure 2 Computed tomography of Spiegel's hernia.

Note: An incarcerated hernia (epiplon) is shown.

Abbreviations: I, bowel; R, right side; S, Spiegel's hernia pouch.

in the 1960s, wrote that this theory was unsatisfactory because of the rarity of blood vessels passing through the defect in the aponeurosis. Another theory, varying from the proposed one, of multiple vessels passing through the defect of the abdominal wall was proposed. Thévenot and Gabourd (1907) suggested the possibility of the aperture at the transversalis fascia causing the possibility of the inferior epigastric artery passing through and perpetually opening the site. ${ }^{23}$ Again, Read disputes this theory due to the "improbability of multiple hernias of Spiegel," which occur in the same location in the abdominal wall in all the descriptions. ${ }^{23} \mathrm{Read}$, in his studies, confirmed that the external oblique muscle is interrupted and divided by "interdigitations of fatty tissue," referring to this fact as a likely pathogenesis of Spiegel's hernia. $^{23}$

River, in 1942, noted in his anatomical studies that the aponeurosis of the transverse muscle of the anterior abdominal wall, the region below the semicircular line (arcuate), often fails congenitally. ${ }^{24}$ In 1944, Zimmerman et al, also through extensive studies of anatomical dissections, eventually found, with some frequency, defects in the aponeurosis and muscle of the semicircular line region, especially in obese individuals, resulting in weakness in the aponeurosis of the transversus and internal oblique muscles. ${ }^{25,26}$

In embryological terms, White, Larson, and Farley reported in their studies that congenital Spiegel's hernia is related to a defect in the edge of the junction between the semilunar and semicircular lines (a weak point at which the semilunar line and the semicircular line of Douglas cross), which usually occurs in 3-day-old to 4-week-old infants. ${ }^{27,28}$ However, the theory of preexisting congenital muscular defect must remain open to new studies. For instance, a case diagnosed and related by Antony and Medlery demonstrated a bilateral "congenital" Spiegel's hernia in a 13-year-old boy based on data from family history of a snag since birth. ${ }^{18}$

It should be noted that the occurrence of aponeurotic defects is not uncommon (35\%) in cases of children in whom Spiegel's hernia is diagnosed. Studies show that in $19 \%$ of Spiegel's hernia cases, there is the presence of ipsilateral inguinal hernias, besides the association of cryptorchidism..$^{21,29,30}$

Embryological origins can be speculated because of the most common site of Spiegel's hernia. The hernia is located below the umbilical area of Spiegel's aponeurosis, which is called the "Spiegel hernia belt." It measures $6 \mathrm{~cm}$ in a transverse zone above the imaginary line between the two anterior-superior iliac spines.

It is very important to review the correct definitions of "aponeurosis" and "fascia." Aponeurosis is, in most cases, a larger than average tendon. Frequently, this tendon is a thin, but strong, sheet of connective tissue, and like a tendon, it is the continuation of an abdominal muscle. Fascia is a tissue that connects each muscle with its respective aponeurosis and/or other tissues. Therefore, in cases of Spiegel's hernia, the more appropriate term would be "Spiegel's aponeurosis" and not "Spiegel's fascia." 
The majority of studies review the importance of good development and strengthening of the muscles of the abdominal wall in reducing the occurrence of Spiegel's hernia. Perhaps, visceral or preperitoneal fat increase can be considered an etiological factor for Spiegel's hernia. Visceral fat dissects aponeurotic fibers and opens the way for a hernia in the aponeurosis of Spiegel. ${ }^{31-34}$

\section{Discussion}

Adriaan van den Spiegel, in 1645, first described the semilunar line (Spigelian line).

In the book "Divisionem Herniarum, Novam-que Herniae Ventralis Speciem," presented and published in 1764, in "Anatomicas Sectiones, et Demonstrationes Publicas Hyemales," Josef Thaddaei Klinkosch, ,6,35,36 for the first time, defined Spiegel's hernia as a defect in the semilunar line. Spiegel's hernia usually occurs between the ages of 40 years and 70 years. However, this age group is increasing, due to the large number of obese adolescents undergoing strong physical activity seeking greater weight loss, and due to physical activity practiced by women who are obese and over 70 years old. ${ }^{10,36}$

Defects in the aponeurosis of the transverse abdominal muscle (mainly under the arcuate line and more frequently in obese patients) have been determined to be the principal etiology. ${ }^{4,36}$ Other predisposing factors are pregnancy and chronic bronchopneumopathies, as well as practice of sports with heavy weights and without proper care and guidance. ${ }^{8,29}$ Because the main aponeurotic tissue of the hernial ring is very strong, showing how rigid and inelastic the hernial ring is, it causes the highest frequency of cases of incarceration and/or strangulation of the bowel, causing obstruction or acute ischemia. ${ }^{35}$ Meanwhile, taking into account the possibility of subacute occlusive syndrome, many cases of which are received in the emergency room, correct diagnosis occurs in less than $30 \%$ of cases. ${ }^{29}$ The occurrence of incarceration of bowel organs in cases of Spiegel's hernia occurs in approximately $20 \%$ of diagnosed cases. ${ }^{37}$

Spiegel's hernia is frequently misdiagnosed, principally in obese and very obese patients and, sometimes, in pregnant women. The presence of a little "ball" at the right abdominal flank or inferior iliac fossa can be confused with an excess of subcutaneous fat, which is very common in obese women.

In total, only $50 \%$ of Spiegel's hernia cases are diagnosed preoperatively. ${ }^{6,12,30}$ The differential diagnoses are most often lipoma, seroma, or posttrauma hematoma of the abdominal wall, as well as joint pathologies. Other differential diagnoses are tumor of the abdominal wall, spontaneous hematoma of the rectus sheath, acute diverticulitis, or even acute appendicitis and appendiceal abscess. In the emergency room, it is important to conduct an ultrasound examination as a first approach to correctly diagnose the bulge of the abdominal wall. To supply more information regarding the real abnormalities of the abdominal wall, and the morphological and anatomic features of the swelling, the "gold standard" radiologic test is the CT scan with oral contrast of the abdominal wall. Besides providing a correct diagnosis, a CT scan is also important to reveal the contents of the hernia and/or any complication. In some cases, Spiegel's hernia is diagnosed only during an exploratory laparotomy or laparoscopy, which are indicated because of different clinical diagnoses, and is treated as the secondary course of action. . $^{8,13,28,36,38}$

Spiegel's hernia ( $1 \%-2 \%$ of all hernias) occurs through a flaw on the fascia of the lateral aponeurosis of the transversus abdominis muscle to the rectus abdominis muscle, often at the arcuate line, where the fascia is the widest and weakest (aponeurosis of the Spiegel or the "Spiegel hernia belt"). It is the protrusion of preperitonial fat, peritoneal sac, or organ(s) of the abdomen, through a congenital or acquired defect in the aponeurosis of Spiegel. Spiegel's hernias usually contain within them the small bowel or omentum. However, other organs may be present in such herniation, eg, colon, stomach, gallbladder, diverticulum, bladder, leiomyoma of the uterus, and even ovary and testis. ${ }^{4}$ Normally, this hernia occurs more often on the medial-lateral left quadrant of the abdominal wall. ${ }^{4,39}$

Great care must be taken not to create iatrogenic future Spiegel's hernia when performing laparoscopic surgeries with trocars or drains that are placed at/on the aponeurosis of Spiegel.

Despite this hernia corresponding to $1 \%-2 \%$ of all types of hernias because of the small internal orifice with a strong fibrosis ring, it is not uncommon that Spiegel's hernia is evaluated as strangulation; so, a correct and earlier diagnosis is very important, and surgery should not be delayed. ${ }^{434,40}$

Richter's hernia (first scientific description was in 1778 by August Gottlieb Richter) may be defined as an abdominal hernia in which only part of the circumference of the intestine is incarcerated and strangulated in the orifice of the hernia. It has also been reported to occur with Spiegel's hernia., ${ }^{40,41}$ For this reason, the indication for surgery should be early and all the risks as well as the importance of the procedure should be reported to patients and their families.

The initial form of and further extensions to the recent and past treatments for Spiegel's hernia have been the 
surgical approach and conventional external management. Initially, only the suturing of the hernia aponeurotic ring was performed, and more recently, implantation of meshes is also carried out.

The laparoscopic treatment for hernia began in the late 1990s, when the mesh implant started to be used, and it was applied in some cases of recurrence.

It is absolutely necessary to use mesh with reabsorbable composite material on the peritoneal side and nonabsorbable material on the abdominal wall side, besides the routine use of absorbable sutures, polydioxanone (PDSII 2-0; Ethicon Inc., Cincinnati, OH, USA), and complementation with absorbable clasps (SecureStrap ${ }^{\mathrm{TM}}$; Ethicon). The reperitonization is performed whenever possible, despite the doublesided mesh with extra protection action. ${ }^{17,42-45}$ Afterward, the reduction of the hernial pouch and, eventually, other organs within it (ileum, colon, omentum, etc) is accomplished. This is facilitated by tissue fixation with arm two of the robot and dissection by the surgeon using the arms one and three of the robot (the da Vinci Robotic System; Intuitive Surgical, Inc., Sunnyvale, CA, USA). Step by step, all the procedures of the surgery are achieved in this manner. The free $360^{\circ}$ rotation of the wrist of the robotic arm facilitates the easy and quick suturing of the fibrous ring of the hernia, as well as the placement of sutures and staples on the mesh. The mean time of surgery was 1.5 hours (90 minutes), blood loss was less than $100 \mathrm{~mL}$, and time in hospital after surgery was 36 hours. All these indices are similar to those in the laparoscopic approach. ${ }^{46-53}$

The use of robotics brought clear advantages related to where robotic technology is based. The ease and visibility for peritoneal dissection of the abdominal anterior-superior wall, due to the yaw at the wrist and the optical rotation, combined with tremor filtration, brings greater effectiveness, safety, and accuracy of dissection and suturing of Spiegel's hernia (Figures 3 and 4).

The approach with the "seven degrees of freedom" (in/out, rotation, pitch at wrist, yaw at wrist, pitch at fulcrum, yaw at fulcrum, and grip strength) plus tremor filtration, motion scaling, and potential aiding of fine movements that the robot technique offers does seem to help decrease blood loss and to promote a safer and better visualization and dissection of structures and can, in addition, reduce the chief surgeon's fatigue and stress (Table 1). However, the harmony between the surgeon who is operating through the console and the robot assistants in the surgical field and alongside the patient should be perfect and they must have undergone extensive training. All surgeons in the surgical team should have the technical training and skill to take the chief surgeon's place at the console, should it be necessary.

There are many considerations that the presence of abdominal muscles is a possible cause; however, electromyography performed in patients with operated Spiegel's hernia never showed any anomaly of this type. ${ }^{32}$

Sir Astley Paston Cooper, brilliant British surgeon and anatomist, demonstrated in his studies that hernias could also occur in small openings in structures through which blood vessels and nerves flow. The aponeurosis of Spiegel has enlargements that pass perforating vessels and nerves that accompany the deep inferior epigastric artery. ${ }^{33}$ An important branch of deep inferior epigastric artery may perforate the rectus abdominis muscle sheath, in $8 \%-10 \%$ of cases, toward the transversus abdominis muscle. It can be through this hole that the imbrications of its aponeurosis with the internal oblique muscle occur and it is the cause of Spiegel's hernia. Nevertheless, the presence of Spiegel's hernia can also be found below and medial to the inferior epigastric artery (ie, in the Hesselbach triangle). In this case, they are called low Spigelian hernias. ${ }^{4,34}$

Laparoscopic surgery has been used to treat abdominalpelvic hernias since 1992, with better results and improved techniques since the mid-1990s. As Spiegel's hernia is a very rare disease, we have only operated on five cases in the last 20 years using the laparoscopic approach, and in all cases we used mesh in the repair.

Robotics surgery, which became the most used surgical method to treat disorders of the digestive tract after 1996, proved to be an excellent tool for surgeries of the anterior abdominal wall hernias. The features and advantages related to three-dimensional vision and direct vision (because

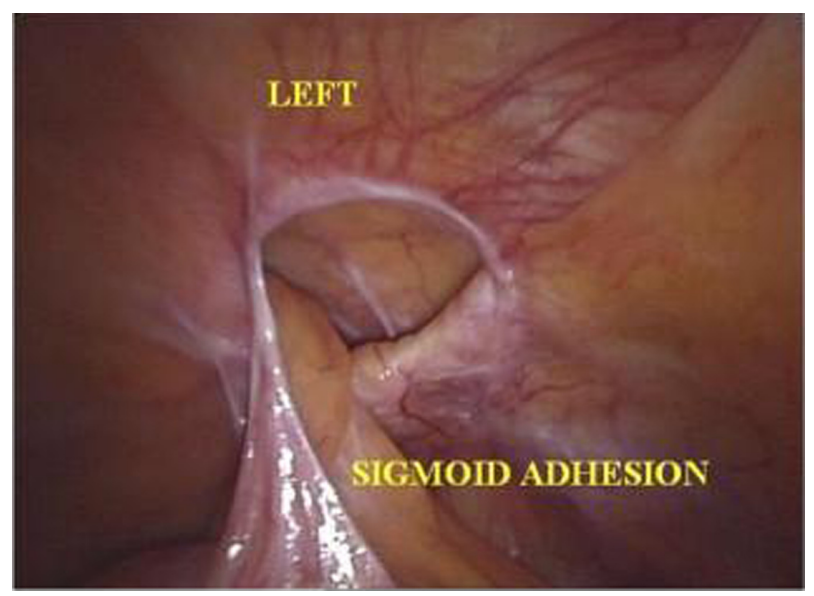

Figure 3 Laparoscopic-robotic view of Spiegel's hernia, with the hernia ring and incarcerated epiplon and the part of sigmoid colon in the hernial pouch. 


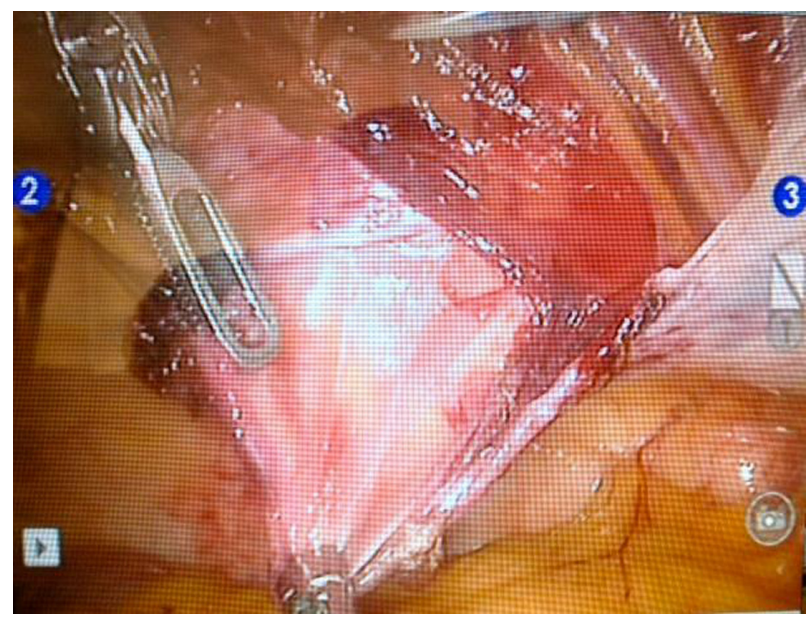

Figure 4 Robotic view of Spiegel's hernia.

Notes: Presence of the dissection of incarcerated tissue and hernial pouch. 2 and 3 represent Arm 2 and Arm 3 of the robot, respectively.

the robot's camera rotates $360^{\circ}$ ), as well as the conditions favorable for suture techniques (also due to the $360^{\circ}$ rotation of the robot gripper), camera stability, fixation without tremors on screen during the suturing, and the fixed auxiliary arm, show the superiority of this new approach relative to the laparoscopic procedure (Table 2 and Figures 5-7).

Because Spiegel's hernia is a very rare disease, the majority of publications are on related cases. In our case, we operated five cases of Spiegel's hernia by the laparoscopic approach in the last 20 years and two cases by robotic surgery (Table 3).

Because of our large experience in laparoscopic surgery (since 1989) and in very complex procedures that use laparoscopic surgery, in addition to our experience with robotic surgery since 2008 and complex surgeries such as pancreatectomy, colon and rectum surgeries, hiatal hernia, and esophagectomy performed with this new tool in the last 3 years, we can conclude that there are real and clear advantages of robotic surgery in Spiegel's hernia repair when compared to laparoscopic surgery, despite the inevitably small number of cases.

Table I Advantages in robotic surgery (seven degrees of freedom of movement)

I. In/out

2. Rotation

3. Pitch at wrist

4. Yaw at wrist

5. Pitch at fulcrum

6. Yaw at fulcrum

7. Grip strength
Both patients who underwent robotic surgery had complete resolution of pain at the sites of Spiegel's hernia and disappearance of the bulges evidenced in such locations in the postoperative period. None of the patients had any adverse reaction to the mesh deployed or any complaint regarding the surgical wounds.

There was a follow-up period of 1 year and 18 months for each case, which showed no problems in spite of the patients' normal daily activities. There were no postoperative seroma formations. Control postoperative radiograph after 6 months demonstrated perfect location of meshes deployed.

For cases of hernias on the anterior wall of the abdomen, the use of the robotics approach seems easier, due to the rotation of $360^{\circ}$, the camera use, the surgical forceps, and visualization of anatomical defects, as well as the realization of the sutures and fixation of the mesh. In a purely laparoscopic technique, suture maneuvers, as well as the visualization of the defect requires difficult maneuvers or improper handling of surgical material.

The death rate was zero in all patients subjected to laparoscopic approach and robotics-assisted technique. In four of five cases of Spiegel's hernia correction by laparoscopy, it was not possible to suture the peritoneum to cover the visceral side of the mesh, whereas in the cases of robotic surgery, both visceral and parietal peritoneal layers were sutured with relative ease. Patients undergoing robotic surgery did not complain of pain after the procedure. Three of the patients had pain with laparoscopic technique on the trocar sites, so it was necessary to introduce analgesics until the tenth postoperative day.

The surgery was $\$ 3,000$ USD more expensive with the robotic technique. In both techniques, the esthetic result was identical. There was greater satisfaction according to unsolicited comments in cases of robotic surgery patients.

Table 2 Robotic versus laparoscopic approach

Robotic surgery

- Three-dimensional imaging

- Fixed third-arm retraction

- Precision needs less time for the learning curve

- Advantages in complex surgical tasks

- Greater precision of movement reproduction of human wrist movements

Laparoscopic surgery

- Two-dimensional imaging

- Fulcrum effect postsite

- Restricted degrees of freedom of instrumentation need more time for the learning curve

- Rectal dissection - more challenging 

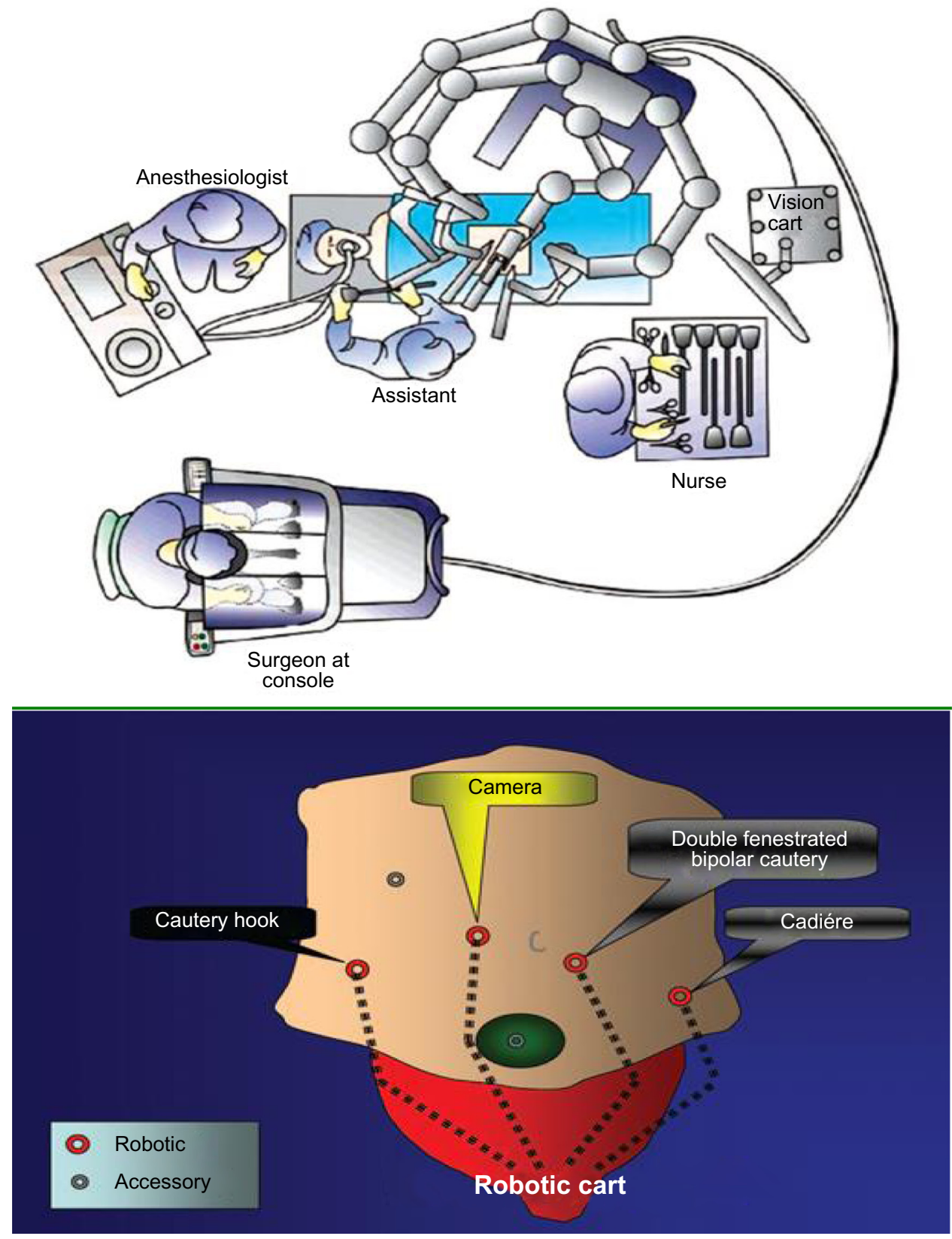

Figure 5 Positions of robot, surgical team, and trocars.

One of these patients had been operated for inguinal hernia by laparoscopy 5 years ago.

The laparoscopic approach for inguinal and abdominal wall hernias was a major advance for surgical treatment at the end of the 20th century (Table 3).

The two patients presented here were referred to our department with suspected inguinal hernia (one case) and incisional hernia (Pfannenstiel incision). In both cases, the bulge was on the left abdominal hypochondrium, and in the case related to possible inguinal hernia, the hernia had "dissected" after passing through the aponeurosis of Spiegel on the lateral border of the inferior rectus muscle, the space between the aponeurosis of external and internal oblique muscles, and "down" to the ipsilateral inguinal region. In both cases, patients had pain at the site, and one of them had a significant worsening of pain during anterior abdominal flexion. In this patient, physical examination clearly showed the presence of an incarcerated intestinal loop, but without signs of inflammation in the region. This finding was confirmed by CT. 


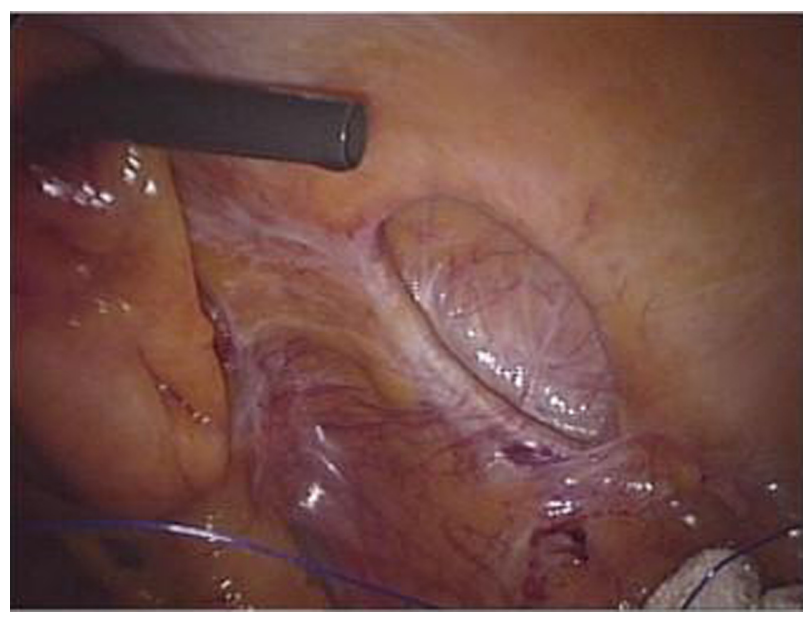

Figure 6 Spiegel's hernia - robotic view of the fibrous ring and hernia cavity with the possibility of free $360^{\circ}$ rotation of robotic camera.

In all cases of incisional hernia in the pelvis, as well as in inguinal hernias with more groin bulging over the inguinal region, we have performed a diagnostic CT scan.

In both cases, the sutures were made after dissection of the hernia ring with polydioxanone in "Greek bar" with a double-sided mesh overlay (siliconized surface) and the peritoneum was sutured over the mesh. Fixing the mesh was made with four "shots" of AbsorbaTack" ${ }^{\mathrm{TM}}$ staples at the cardinal points, and the remaining area was fixed using glue with the tip of laparoscopic applicator. The mean follow-up time in both cases was 10 months. Abdominal radiograph controls of the positioning of the meshes were obtained during the follow-up of patients.

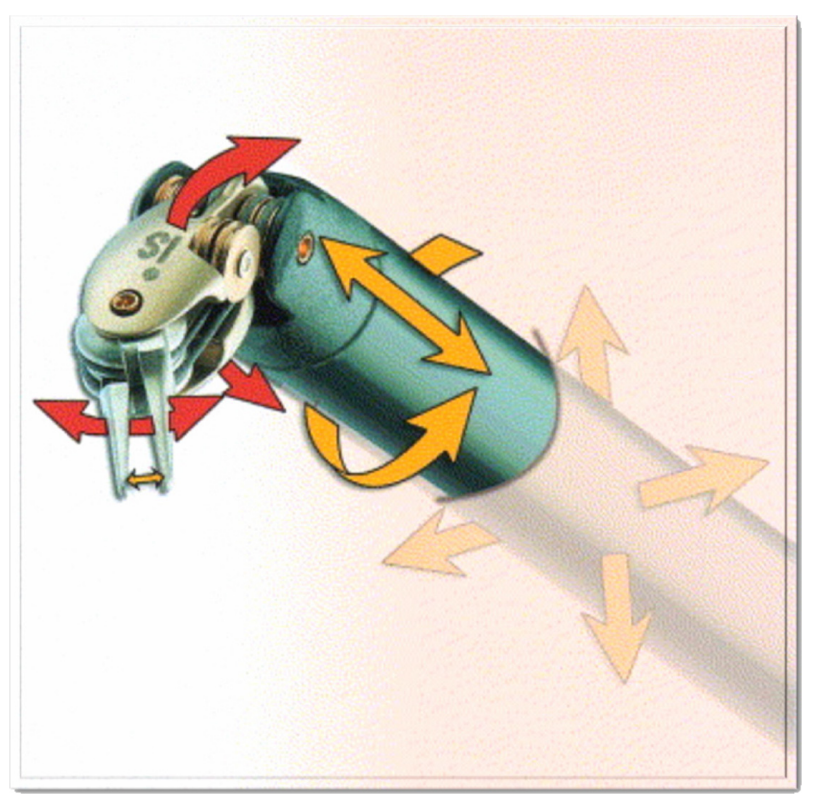

Figure 7 Facilities of robotics instrument in surgery.
Table 3 Reported robotic and laparoscopic surgeries for the repair of Spigelian hernia in the English literature

\begin{tabular}{|c|c|c|}
\hline First author & Year & Method \\
\hline \multicolumn{3}{|c|}{ Laparoscopic suture closure } \\
\hline Carter' & 1992 & $\begin{array}{l}\text { Laparoscopic suturing and } \\
\text { extracorporeal suturing }\end{array}$ \\
\hline \multicolumn{3}{|c|}{ Robotic-assisted technique } \\
\hline Pirolla & 2014 & $\begin{array}{l}\text { Robotic surgery using Physiomesh }{ }^{\circledast}, \\
\text { BioGlue }^{\circledR} \text {, SecureStrap }{ }^{\mathrm{TM}}, \text { PDS } \|^{\circledR} \\
\text { intraperitoneal onlay mesh }\end{array}$ \\
\hline De Matteo ${ }^{36}$ & 1993 & Stapled Gore-Tex ${ }^{\circledR}$ patch \\
\hline Fisher ${ }^{16}$ & 1994 & $\begin{array}{l}\text { Stapled marlex mesh and with } \\
\text { peritoneal flap }\end{array}$ \\
\hline Barie $^{6}$ & 1994 & Polyester/polyglactin 910 mesh \\
\hline Novell ${ }^{7}$ & 2002 & Polypropylene mesh \\
\hline Appletans ${ }^{8}$ & 2002 & ePTFE mesh after coagulation of sac \\
\hline $\mathrm{Habib}^{3}$ & 2002 & Stapled Gore-Tex ${ }^{\circledR}$ mesh \\
\hline Moreno - Egea ${ }^{15}$ & 2002 & $\begin{array}{l}\text { Composite mesh sutured with } \\
\text { Gore-Tex }{ }^{\circledR} \text { suture passer }\end{array}$ \\
\hline Iswariah ${ }^{2}$ & 2003 & $\begin{array}{l}\text { Onlay mesh after laparoscopic } \\
\text { suture repair }\end{array}$ \\
\hline \multicolumn{3}{|c|}{ Total extraperitoneal patch } \\
\hline Kieturaskis $^{55}$ & 1994 & Polypropylene mesh \\
\hline Moreno-Egea ${ }^{10}$ & 2002 & $\begin{array}{l}\text { Polypropylene mesh fixed } \\
\text { with tacker }\end{array}$ \\
\hline \multicolumn{3}{|c|}{ Transabdominal preperitoneal patch } \\
\hline Felix $^{17}$ & 1994 & $\begin{array}{l}\text { Polypropylene mesh stapled } \\
\text { after fascial closure }\end{array}$ \\
\hline Kasirajan ${ }^{43}$ & 1997 & $\begin{array}{l}\text { Mesh reinforcement after } \\
\text { fascial suturing }\end{array}$ \\
\hline Gedebou $^{44}$ & 1998 & Prolene $^{\circledR}$ mesh \\
\hline Amendolara $^{56}$ & 1998 & $\begin{array}{l}\text { Polypropylene mesh fixed } \\
\text { with titanium clips }\end{array}$ \\
\hline
\end{tabular}

Notes: Gore-Tex ${ }^{\circledast}$ is a trade name for ePTFE. Prolene ${ }^{\circledast}$ is a trade name for polypropylene, Physiomesh ${ }^{\circledast}$ is a trade name for polyester with a three-dimensional weave material (polyglecaprone-25 film and polypropylene mesh; Ethicon), BioGlue ${ }^{\circledR}$ is a trade name for a surgical adhesive composed of bovine serum albumin and glutaraldehyde, SecureStrap ${ }^{\mathrm{TM}}$ is the trade name for the copolymer poly(glycolideco-L-lactide; Ethicon).

Abbreviations: ePTFE, expanded polytetrafluoroethylene.

\section{Conclusion}

In this article exploring an approach hitherto unpublished in the literature, we present the first instance of two robotic surgeries conducted to correct Spiegel's hernia. Certainly, a randomized study with a larger sample size would benefit the community by furthering medical and scientific knowledge related to this new surgical tool. The roboticsassisted surgical approach has proven to be a safe tool and has shown significant advantages for surgical treatment of Spiegel's hernia.

\section{Disclosure}

The authors report no conflicts of interest in this paper. 


\section{References}

1. Netter FH. Netter's Gastroenterology. Carlstadt, NJ, USA: Icon Learning System; 2005.

2. Palanivelu C, Vijay Kumar M, Jani KV, et al. Laparoscopic transabdominal preperitoneal repair of spigelian hernia. JSLS. 2006;10:193-198.

3. Read RC. Observations on the etiology of Spigelian Hérnia. Ann Surg. 1960;152:1004-1008.

4. Skandalakis PN, Zoras O, Skandalakis JE, Mirilas P. Spigelian hernia: surgical anatomy, embryology, and technique of repair. Am Surg. 2006;72(1):42-48.

5. SkandalaKis JE, Gray SW, Monsberger AR. Hérnia: Surgical Anatomy and Technique. New York: McGraw-Hill; 1989.

6. Spiegel A. Opera Quae Extore Omnia. Amsterdam: John Bloew; 1645:103.

7. Moore KL. Clinically Oriented Anatomy. Abdominal Wall. 2nd ed. Philadelphia, PA:Lippincott Williams\&Williams; 1990:105-119.

8. Amendolara M. Videolaparoscopic treatment of Spigelin hérnia. Surg Laparosc Endosc. 1998;8(2):136-139.

9. Felix EL, Michas C. Laparoscopic repair of spigelian hernias. Surg Laparosc Endosc. 1994;4:308-310.

10. Fisher BL. Video-assisted spigelian hernia repair. Surg Laparosc Endosc. 1994;4:238-240.

11. Opson RO, Davis WC. Spigelian hernia: rose on obscure? Am J Surg. 1968;116:842-846.

12. Cruz A, Lerma R, Sánchez-Ganfornina F, Báez F, Muntané J, Padillo FJ. Incarcerated Spigelian hernia: diagnosis by computed tomography. Rev Esp Enferm Dig. 2012;104(11):612-613.

13. Campos SM, Walden T. Images in clinical medicine. Spigelian hernia. N Engl J Med. 1997;336:1149.

14. Rogers FB, Camp PC. A strangulated Spigelian hernia mimicking diverticulitis. Hernia. 2001;5:51-52.

15. Loizon P, Nahon P, Founti H, Delecourt P. Hérnia de Spieghel et mésentere commum: propôs d'une observation. [Spigelian hernia and common mesentery. Apropos of a case]. J Chir. 1992;129(5):285-286. French.

16. Klinkosch JT. Divisionem Herniarium Novamgue Herniae Ventra-lis Proponit [Disertationem Medicorum]. 1764:184. Latin.

17. DeMatteo RP, Morris JB, Broderick G. Incidental laparoscopic repair of spigelian hernia. Surgery. 1994;115:521-522.

18. Le Dran H-F. Traité des operations de chirurgie (Treaty surgical operations). Paris: Charles Osmont; 1742:142. French.

19. La Chausse BI. Dissertatio chirurgica de hérnia ventrali [Dissertation of surgical ventral hernia]. Naples: Gessare; 1756. Italian.

20. Scopinaro AJ. Hérnia on Spigels semilinear line in a newborn. Semana Med. 1935;1:284-285.

21. AL-Salem AH. Congenital spegelian hernia and cryptor chidsm: cause or coincidence? Pediatr Surg Int. 2000;16:433-436.

22. Cooper A. The Anatomy and Surgical Treatment of Inguinal and Congenital Hernia. London: Langman, Hurst, Ress and Osme; 1804.

23. Read RC. Observations on the etiology of Spigelian hernia. Ann Surg. 1960;152:1004-1009.

24. River LP. Spigelian hernia. Ann Surg. 1942;116:405.

25. Zimmerman LM, Anson BJ, Morgan EH, et al. Ventral hernia due to normal banding of the abdominal muscles. Surg Gynecol Obstet. 1944;78:535-540.

26. Arey LB. Developmental Anatomy. 6th ed. Philadelphia: WH Saunders; 1954:182.

27. White JJ. Concomitant spigelian and inguinal hernias in a neonate. J Pediatr Surg. 2002;37:659-660.

28. Larson DW, Farley DR. Spigelian hernia: repair and out-come for 81 patients. World J Surg. 2002;26:1277-1281.

29. Guivarc'h M, Fonteny R, Boche O, Roullet-Audy JC. Hernies ventrales antero-latera les dites de Spighel. [So-called Spiegel's anterolateral ventral hernia. 16 cases and a review of the literature]. Chirurgie. 1988;114:572-578. French.
30. Tsalis K, Zacharakis E, Lambrou I, Betsis D. Incarcerated small bowel in a spigelian hernia. Hérnia. 2004;8(4):384-386.

31. Petronella P, Freda F, Nunziata L, et al. Spigelian hérnia: a rare Lateral ventral hérnia. Chir Ital. 2004;56:727-730.

32. Scopinaro AJ. Hérnia on Spigels semilinear Line in a newborn. Semana Med. 1935;1:284-285.

33. Arey LB. Developmental Anatomy, 6th Ed. Philadelphia: WH Saunders; 1954:182.

34. AL-Salem AH. Congenital spegelian hernia and cryptor chidsm: cause or coincidence? Pediatr Surg Int. 2000;16:433-436.

35. Spangen L. Spigelian hernia. World J Surg. 1989;13:573-580.

36. Sachs M, Linhart W, Bojunga J. [The so-called Spigelian hernia-a rare lateral hernia of the abdominal wall]. Zentralbi Chir. 1998;123(3): 267-271. German.

37. Nozoe T, Funahashi S, Kitamura M, et al. Ileus with incarceration of Spigelian hernia. Hepatogastroenterology. 1999;46(26): 1010-1012.

38. Mittal T, Kumar V, Khullar R, et al. Diagnosis and management of spigelian hernia: a review of literature and our experience. $J$ Minim Access Surg. 2008;4(4):95-98.

39. Zachariah SK, Jose P. Laparoscopic diagnosis of incarcerated "spigelian hernia": report of a case and review of the literature. Case Rep Surg. 2011;2011:491802.

40. Ng JWT. A case of samall spigelian hernias successfully treated by a simple laparoscopy-assisted tecnique. Surg Laparosc Endosc Percutan Tech. 2004;14:300-303.

41. Zimmerman LM, Anson BJ, Morgan EH, et al. Ventral hernia due to normal banding of the abdominal muscles. Surg Gynecol Obster. 1944;78:535-540.

42. Barie PS, Thompson WA, Mack CA. Planned laparoscopic repair of a spigelian hernia using composite prosthesis. J Laparosc Surg. 1994;4:359-363.

43. Geis WP, Crafton WB, Novak MJ, Malago M. Laparoscopic hernia: results and technical aspects in 450 consecutive patients. Surgery. 1993;114:765-772.

44. Wiedeman EJ. The open mesh repair of Spigelian hérnia. Am J Surg. 2008;196:460-462.

45. Celdran A, Senaris J, Mañas J, Frieyro O. The open mesh repair of Spigelian hérnia. Am J Surg. 2007;193:111-113.

46. Tarnoff M, Rosen M, Brody F. Planned totally extraperitoneal laparoscopic Spigelian hernia repair. Surg Endosc. 2002;16(2):359.

47. Kieturakis MJ, Nguyen DT, Vargas H, Fogarty TJ, Klein SR. Balloon dissection facilitated laparoscopic extra peritoneal hernioplasty. Am J Surg. 1994;168:603-608.

48. Gedebou JM, Neubauey W. Laparoscopic repair of bilateral spigelian and inguinal hernias. Surg Endosc. 1998;12:1424-1425.

49. Petronella P, Freda F, Nunziata L, et al. Spigelian hérnia: a rare lateral ventral hérnia. Chir Ital. 2004;56:727-730.

50. Safioleas M, Stamatakos M, Moulakakis K, Safioleas P, Skandalakis P. hernia. A rare case of bilateral hernia and presentation of our experience. Chicurgia. 2004;102(4):429-432.

51. Safioleas M.Stamatakos M, Morlakaks K et al. Spigelian hernia. A rare case of bilateral hernia and presentation of our experience. Chicurgia. 2004;102(4):429-432.

52. Cooper A. The anatomy and surgical treatment of inguinal and congenital hernia. London: Langman, Hurst, Ress \& Osme; 1804.

53. Read RC. Observations on the etiology of Spigelian hernia. Ann Surg. 1960;152:1004-1009.

54. Spangen L. Spigelian hérnia. Surg Clin North Am. 1984;64:351-366.

55. Howlihan TJ. A review of Spigelian hernia. Am J Surg. 1976;131: 734-735. 
Advanced Health Care Technologies

Dovepress

\section{Publish your work in this journal}

Advanced Health Care Technologies is an international, peer reviewed, open access journal that provides a unique forum for articles on: point-of-care, health care diagnostics and treatment, bioengineering, biotechnology, biosensing, electronics, clinical/medical science, chemical engineering, materials science, regenerative medicine, micro-/

nano-technologies, and methods and applications for nanoscience and nanotechnology. The manuscript management system is completely online and includes a very quick and fair peer review system, which is all easy to use. Visit http://www.dovepress.com/testimonials.php to read real quotes from published authors.

Submit your manuscript here: http://www.dovepress.com/advanced-health-care-technologies-journal 